\title{
Visual outcome after emergency surgery for open globe eye injury in Japan
}

This article was published in the following Dove Press journal:

Clinical Ophthalmology

8 September 2016

Number of times this article has been viewed

\author{
Ai Toride ${ }^{1,2}$ \\ Hiroshi Toshida' \\ Asaki Matsui ${ }^{1}$ \\ Yusuke Matsuzaki' \\ Rio Honda ${ }^{1,3}$ \\ Toshihiko Ohta' \\ Akira Murakami ${ }^{3}$ \\ 'Department of Ophthalmology, \\ Juntendo University Shizuoka \\ Hospital, Shizuoka, ${ }^{2}$ Department of \\ Ophthalmology, Juntendo University \\ Nerima Hospital, ${ }^{3}$ Department of \\ Ophthalmology, Juntendo University \\ School of Medicine, Tokyo, Japan
}

\begin{abstract}
Background: Most patients with open globe eye injury are brought to hospital as emergency patients and usually require admission for emergency surgery. We analyzed the visual outcome in patients with open globe eye injury at our hospital over a 4-year period.

Patients and methods: This study reviewed 40 eyes of 40 patients with open globe eye injury who were presented to Juntendo University Shizuoka Hospital and required emergency surgery during the 4 years from January 2010 to December 2014. Retrospective evaluation of the visual outcome was performed using data from the medical records, including assessment of the influence of sex, side of the eye injury, cause of injury, and site/severity of injury.
\end{abstract}

Results: The mean age (SD) at the time of the injury was 58.9 years $( \pm 25.1$ years). There were 28 males $(70.0 \%)$ and 12 females $(30.0 \%)$. Statistically significant improvement in visual acuity after treatment was noted in the males ( $P=0.0015$, Wilcoxon test), but not in the females. Twenty-five patients had injury to the right eye $(62.5 \%)$ and 15 had injury to the left eye (37.5\%). A significant improvement in visual acuity was achieved after treatment of injury to the right eye $(P=0.021)$, but not the left eye $(P=0.109)$. The most frequent cause of injury was an accident ( 15 eyes; $37.5 \%$ ). The second most frequent cause was work-related injury (14 eyes; $35.0 \%$ ), which only occurred in males, and the third cause was accident due to negligence (eleven eyes; $27.5 \%$ ). Two patients developed sympathetic ophthalmia and one patient developed postoperative endophthalmitis.

Conclusion: The majority of patients with open globe eye injury were male workers in Japan. The visual outcome of work-related injury was better than that of injury due to other causes. The visual outcome was also better if the right eye was injured compared with the left eye. Patients with injuries due to negligence were older than the other groups, and this finding might be characteristic of an aging society.

Keywords: ocular trauma, visual outcome, accident, work-related injury, negligence

\section{Introduction}

It is not rare for patients with eye injuries to present to hospital urgently. In particular, open globe eye injuries are often severe enough to require hospitalization and emergency surgery. ${ }^{1,2}$ Open globe eye injury can be due to laceration of the cornea or sclera by sharp objects or blunt trauma (contusion) with rupture of the eye due to a sudden marked increase in intraocular pressure. The site and extent of injury vary widely between patients, with complications depending on whether there is involvement of the crystalline lens, vitreous/retina, and/or optic nerve. ${ }^{2,3}$ If the damage is very severe, enucleation or evisceration of the eyeball may be required. ${ }^{4}$ When the eye can be salvaged, the visual outcome is influenced by the type and site of injury and by complications. We performed a retrospective evaluation of the visual outcome in patients with open globe eye injury to investigate the potential influence of patient
Correspondence: Hiroshi Toshida Department of Ophthalmology, Juntendo University Shizuoka Hospital, I 29 Izunokuni, Shizuoka 4I0-2295, Japan Tel +8I 559483 III

Fax +8I 55948335 I

Email toshida@juntendo.ac.jp (c) (1) (5) 2016 Toride et al. This work is published and licensed by Dove Medical Press Limited. The full terms of this license are available at https://www.dovepress.com/terms.php cc) and incorporate the Creative Commons Attribution - Non Commercial (unported, v3.0) License (http://creativecommons.org/licenses/by-nc/3.0/). By accessing the work you hereby accept the Terms. Non-commercial uses of the work are permitted without any further permission from Dove Medical Press Limited, provided the work is properly attributed. For permission for commercial use of this work, please see paragraphs 4.2 and 5 of our Terms (https://www.dovepress.com/terms.php). 
characteristics, the side affected (right or left eye), the cause of injury, and the extent of injury.

\section{Patients and methods}

This study was performed in accordance with the Helsinki Declaration of 1975 , as revised in 2008, and written informed consent was obtained from each patient before the patients received surgeries. This study reviewed 40 eyes of 40 patients with open globe eye injury who were presented to Juntendo University Shizuoka Hospital and required emergency surgery during the 4 years, from January 2010 to December 2014. Retrospective analysis of data from the medical records was performed, and approved by the institutional ethics committee of Juntendo University Shizuoka Hospital. The items evaluated were age, sex, side of injury (right or left eye), cause of injury, site/severity of injury, operative procedure, and visual outcome. The presence or absence of intraocular damage, complications, and intraocular foreign bodies was also investigated to assess the severity of eye injury.

Visual acuity was measured with a Snellen chart, and the results were transformed to logarithm of the minimum angle of resolution (LogMAR) values for analysis. ${ }^{5}$ Furthermore, patients were classified into three groups based on the cause of injury: 1) accidents including traffic accidents and injury due to foreign bodies such as a fish hook, a chip of glass, or a peg; 2) work-related injuries; and 3) accidents due to negligence. The Wilcoxon $t$-test was used for comparisons between pre- and postoperative visual acuity, while the Tukey-Kramer multiple comparison test was used comparing three groups, and $P<0.05$ (two-tailed test) was considered to indicate statistical significance. Results are shown as mean \pm standard deviation (SD).

\section{Results}

\section{Age and sex}

The mean age of the 40 patients ( 40 eyes) was $58.9 \pm 25.1$ years (range: 4-98 years), and they included 28 males (70.0\%) and 12 females $(30.0 \%)$. When visual acuity before and after treatment was assessed separately in males and females, LogMAR visual acuity was $1.845 \pm 1.145$ before treatment and $0.789 \pm 1.102$ after treatment in males, showing a statistically significant improvement $(P=0.002$, Wilcoxon $t$-test; Table 1). In females, LogMAR visual acuity was $2.264 \pm 1.311$ before treatment and $2.178 \pm 1.003$ after treatment, and the difference was not significant $(P=0.328)$.

\section{Side of injured eye}

The injured eye was the right eye in 25 patients $(62.5 \%)$ and the left eye in 15 patients (37.5\%); hence, approximately two-thirds of the patients had injury to the right eye. Visual acuity was compared between before and after treatment separately for the right and left eyes. In the patients with injury to the right eye, $\operatorname{LogMAR}$ visual acuity was $1.966 \pm 1.155$ before treatment and $1.194 \pm 1.234$ after treatment, with statistically significant improvement being observed (Wilcoxon $t$-test, $P=0.021$; Table 1 ). In the patients with injury to the left eye, $\operatorname{LogMAR}$ visual acuity was $1.896 \pm 1.263$ before treatment and $1.386 \pm 1.257$ after treatment, with the difference not being significant $(P=0.109)$.

\section{Concomitant injuries and intraocular foreign bodies}

Concomitant external eye injuries included eyelid laceration $(n=4)$ and orbital floor fracture $(n=3)$. Regarding concomitant intraocular injuries, the iris was involved in 26 eyes (50.1\%), including prolapse $(n=12)$, other iris injury $(n=2)$, and impaction $(n=2)$. The second most frequent type of concomitant intraocular injury was injury to the lens in nine eyes $(28.2 \%)$, including traumatic cataract $(n=6)$, expulsion of the lens $(\mathrm{n}=2)$, and lens subluxation $(\mathrm{n}=1)$. In addition, vitreous prolapse occurred in seven eyes (21.9\%).

Intraocular foreign bodies were identified in seven eyes (21.9\%), and these foreign bodies were located in the cornea $(n=3)$, vitreous $(n=3)$, and anterior chamber $(n=1)$. The most common foreign body was a piece of metal (iron), which was seen in four eyes, while other foreign bodies included pieces of concrete and glass.

Table I Characteristics of patients with open globe eye injury stratified by sex and affected side

\begin{tabular}{lllll}
\hline Characteristics & Number (\%) of eyes & \multicolumn{2}{l}{ Visual acuity (LogMAR) } & After surgery \\
\cline { 3 - 4 } & & Before surgery & $0.789 \pm 1.102$ & 0.002 \\
\hline Male & $28(70.0)$ & $1.845 \pm 1.145$ & $2.178 \pm 1.003$ & 0.328 \\
Female & $12(30.0)$ & $2.264 \pm 1.311$ & $1.194 \pm 1.234$ & 0.021 \\
Right eye & $25(62.5)$ & $1.966 \pm 1.155$ & $1.386 \pm 1.257$ & 0.109 \\
Left eye & $15(37.5)$ & $1.896 \pm 1.263$ & & \\
\hline
\end{tabular}

Notes: LogMAR visual acuity in males showed statistically significant improvement $(P=0.002$, Wilcoxon $t$-test). In the patients with injury to the right eye, LogMAR visual acuity improved statistically (Wilcoxon $t$-test, $P=0.021$ ).

Abbreviation: LogMAR, logarithm of the minimum angle of resolution. 
Table 2 Total number of primary operations in 40 patients

\begin{tabular}{ll}
\hline Procedures & $\begin{array}{l}\text { Total number } \\
\text { of operations }\end{array}$ \\
\hline Scleral suture & 19 \\
Corneal suture & 15 \\
Vitrectomy & 11 \\
Washout anterior chamber & 6 \\
Removal of intraocular foreign body & 5 \\
Lensectomy & 4 \\
Iridectomy & 4 \\
Enucleation & 3 \\
Removal of intraocular lens & 3 \\
Insertion of intraocular lens & 2 \\
Silicone oil tamponade & 2 \\
Gas tamponade & 2 \\
Eyelid suture & 2 \\
Amniotic membrane transplantation & 1 \\
\hline
\end{tabular}

\section{Surgical procedures}

Primary surgery was performed in 28 of 40 eyes with sclerocorneal laceration $(70.0 \%)$ on the day of injury and on the next day in six eyes (18.8\%). Details of the primary operations are shown in Table 2. More than half of the eyes (22/40 eyes; $55.0 \%$ ) required reoperation. The second operation involved vitreous surgery in eight eyes, which was done because of retinal detachment ( $n=7)$, vitreous hemorrhage $(n=3)$, proliferative vitreoretinopathy $(n=2)$, or expulsive hemorrhage $(n=1)$. Other operative procedures were cataract surgery or secondary intraocular lens implantation $(n=4)$, corneal transplantation $(\mathrm{n}=3)$, amniotic membrane transplantation $(\mathrm{n}=1)$, and anterior chamber irrigation $(\mathrm{n}=1)$.

\section{Visual outcome}

The results of visual acuity were evaluated divided by based on the cause of injury (Table 3 ). The most frequent cause of injury was an accident (eg, traffic accident) in 15 eyes (37.5\%). The second most frequent cause was work-related injury, which occurred in 14 eyes (35.0\%). The third cause of injury was an accident due to negligence, which was the cause of injury in eleven eyes (27.5\%; Figure 1).

\section{Accidents}

In injured eyes by accidents, there were 15 eyes of 15 patients, including eleven males (73.3\%) and four females (26.7\%).
The mean age of the 15 patients was $48.8 \pm 29.9$ years (range: 9-98 years), and LogMAR visual acuity was $2.059 \pm 1.258$ before treatment and $1.586 \pm 1.325$ after treatment, with the difference not being statistically significant $(P=2.000)$. In addition, there were six right eyes and nine left eyes; hence, injury largely occurred on the left eye.

\section{Work-related injury}

Work-related injury was defined as any eye injury occurring when the patient was working. All of the patients in this group were males, their mean age was $51.7 \pm 15.1$ years (range: 26-77 years), and injury occurred to eleven right eyes and three left eyes; hence, work-related injury largely occurred on the right eye. In these eyes, LogMAR visual acuity was $1.335 \pm 1.117$ before treatment and $0.305 \pm 0.644$ after treatment, and a significant improvement was observed ( $P=0.018$, Wilcoxon $t$-test).

\section{Accidents due to negligence}

This category included accidents such as falling over furniture. There were three males and eight females in this group, with eight right eyes and three left eyes being involved. In the eyes injured by this mechanism, LogMAR visual acuity was $2.840 \pm 0.055$ before treatment and $2.160 \pm 0.767$ after treatment, and the difference was not significant $(P=0.109)$. The mean age of the eleven patients was $81.8 \pm 10.1$ years (range: 59-94 years), which was significantly older compared with the other two causes of injury ( $P=0.007$, Tukey-Kramer test).

\section{Postoperative complications}

Evaluation of postoperative complication was performed in 37 patients, excluding three patients who had enucleation of the eyeball. In two of the 37 patients (5.4\%), sympathetic ophthalmia developed at an average of 1.5 months after injury. Both eye injuries were caused by accidents due to negligence and were severe, losing light reflex in the eye on presentation to hospital. Case 1 was a 78-year-old man who fell against a bookshelf and suffered contusion of his right eye. He presented with sclerocorneal laceration, anterior chamber bleeding, iris prolapse, and vitreous prolapse. Expulsive

Table 3 Cause of injuries, characteristics, and visual outcome

\begin{tabular}{llllllllll}
\hline Cause of injury & $\begin{array}{l}\text { Number (\%) } \\
\text { of the eyes }\end{array}$ & $\begin{array}{l}\text { Age (years), } \\
\text { mean } \pm \text { SD }\end{array}$ & & & & & \multicolumn{3}{l}{$\begin{array}{l}\text { Before surgery } \\
\text { After surgery }\end{array}$} \\
\hline I. Accidents & I5 (37.5) & $48.8 \pm 29.9$ & II & 4 & 6 & 9 & $2.059 \pm 1.258$ & $1.586 \pm 1.325$ & 2.000 \\
2. Work-related injury & I4 (35.0) & $51.7 \pm 15.1$ & 14 & 0 & II & 3 & $1.335 \pm 1.117$ & $0.305 \pm 0.644$ & 0.018 \\
3. Accidents due to negligence & II (27.5) & $81.8 \pm 10 . I^{*}$ & 3 & 8 & 8 & 3 & $2.840 \pm 0.055$ & $2.160 \pm 0.767$ & 0.109 \\
\hline
\end{tabular}

Notes: The patients with open globe eye injury caused by accidents due to negligence had a higher mean age than those with open globe eye injury due to accidents or work-related injuries $\left({ }^{*} P=0.007\right.$, Tukey-Kramer test). In work-related injured eyes, LogMAR visual acuity was improved statistically $(P=0.018$, Wilcoxon $t$-test).

Abbreviations: LogMAR, logarithm of the minimum angle of resolution; SD, standard deviation. 


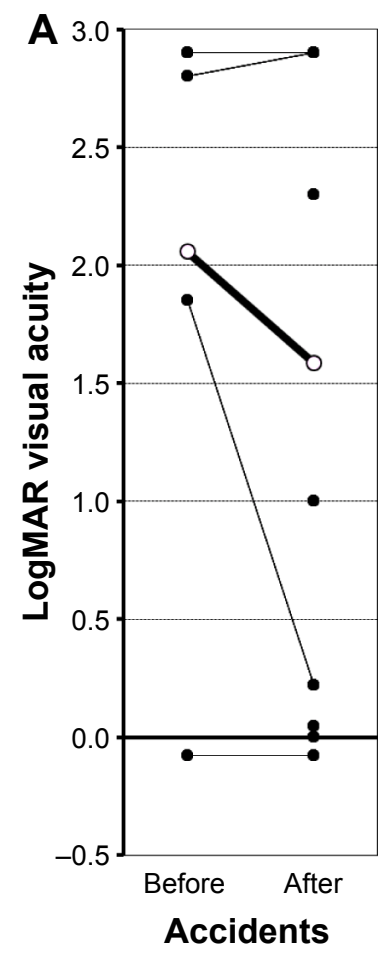

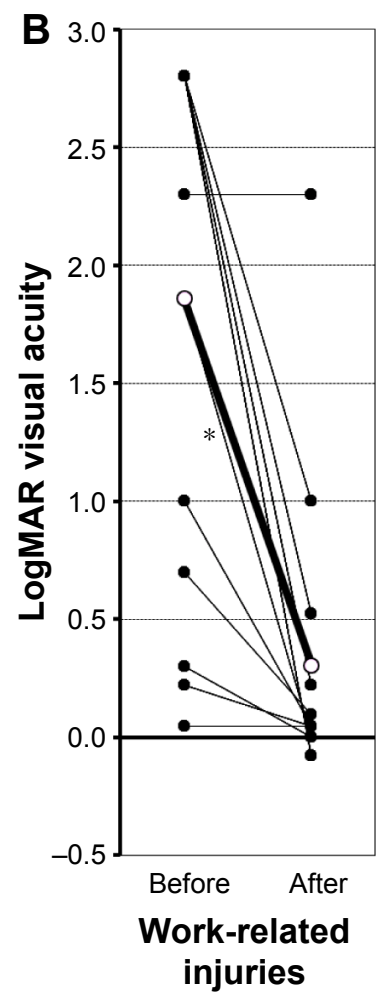

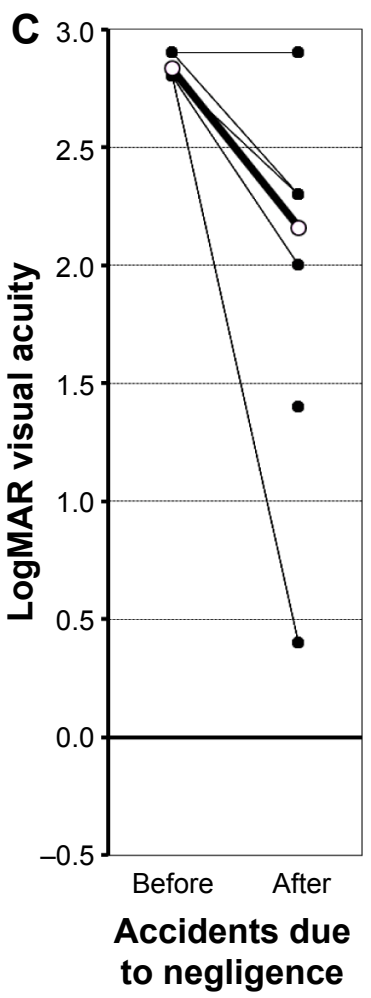

Figure I Comparison of visual acuity (LogMAR) before and after treatments.

Notes: Causes of injury: (A) accidents, $(\mathbf{B})$ work-related injuries, and $(\mathbf{C})$ accidents due to negligence. The bold line shows mean value in each. In work-related injuries, significant improvement was observed after surgeries $\left({ }^{*} P=0.018\right.$, Wilcoxon $t$-test).

Abbreviation: LogMAR, logarithm of the minimum angle of resolution.

hemorrhage occurred during surgery on the next day for suture of the sclerocorneal laceration and vitrectomy. Case 2 was a 65 -year-old man who was injured when the clasp of a dog lead hit his left eye while he was walking a dog. Like Case 1, this patient presented with sclerocorneal laceration, anterior chamber bleeding, iris prolapse, and vitreous prolapse. Scleral suture and vitrectomy were performed on the day of injury. Retinal detachment was noted on the next day and an encircling procedure was performed. In both patients, steroid pulse therapy was given as treatment for sympathetic ophthalmia. In one eye (2.5\%) of a 61-year-old male, infectious endophthalmitis was developed 1 day after removal of intraocular foreign body and suture for a sclerocorneal laceration. After receiving anterior chamber irrigation with antibiotics and intravitreal antibiotics injection, his visual acuity recovered to $20 / 20$, probably because prophylactic administration of antibacterial agents was effective.

\section{Discussion}

The age of patients with open globe eye injury was higher in Japan (58.9 years) than other countries. ${ }^{6-16}$ The elderly population is progressively increasing in developed countries, especially Japan. This study also revealed that a relatively high proportion of eye injuries in elderly persons were caused by accidents due to negligence, corresponding to a report from Scotland. ${ }^{16}$ The number of senior citizens injured by fall and bruise injured was also relatively large. In the present study, the ratio of work-related injuries was lower in Japan (35\%) than other counties. ${ }^{6-16}$ In contrast, in some countries, patients were injured due to conflict, war, or gun crime, and many of the patients with open globe eye injury were young men. However, there were no patients of such cases in the present series. Previous reports. ${ }^{6-16}$ showed that the ratio of the causes of work-related injuries were more than half, although the ratio of work-related injury was $\sim 1 / 3$ in the present study. The results of our study cannot be easily compared with reports from other countries. In Japan, open globe eye injury tends to affect elderly people, and there are almost no injuries due to war or conflict.

In the present study, the male-female ratio of patients with open globe eye injury was 7:3. Male patients were predominant, as in previous reports, ${ }^{6-16}$ but the proportion of female patients was not so small. Sex differences persisted with females more likely to have injuries from a fall or in the home as previously reported. ${ }^{9,15,16}$ The majority of patients with injuries related to work were male; 
a finding similar to the previous studies. ${ }^{17,18}$ Comparison of visual acuity before and after treatment only demonstrated a statistically significant improvement in the male patients. There were probably two reasons for this finding. The first reason was that all of the work-related eye injuries occurred in males. This was the only one group that had a statistically significant improvement in visual acuity after treatment. The second reason was that most of the cases of workrelated eye injury tended to be relatively mild, belonging to Zone 1 (12/14 patients, $85.7 \%$, data not shown) in a severity classification. ${ }^{2}$ Therefore, the visual outcome of work-related eye injury was better than the visual outcome of injuries due to other causes, and this may have led to the better outcome in males compared with females.

Another interesting finding was the side of the affected eyes. Since the right/left ratio was 5:3, the majority of the injured side was right. Although, information on handedness was not collected in this study, the ratio for the righthanded person is reported to be approximately $95 \%$ among Japanese. ${ }^{19}$ Generally, it is inferred that the people used tools such as a hammer or a drill in handedness. So, it seemed that the same side of the eyes and handedness tended to be injured.

A comparison of visual acuity before and after treatment revealed statistically significant improvement in patients with injury on the right eye, but not the left eye. The number of injured right eyes was higher, so a significant difference might have been achieved more easily for the right eye. In the present series, nine patients had contusion of the eyeball, which resulted in monocular blindness in three patients and binocular blindness in one patient. In people with preexisting visual impairment, the eye with better visual acuity is more likely to suffer contusion because people depend on the healthier eye in daily living and use it to view objects closely.

Intraocular bacterial infection is a common complication of open globe eye injury, and it was reported that the incidence is $3.2 \%$. In the present series, only one eye of the 40 patients with sclerocorneal laceration developed infectious endophthalmitis $(2.5 \%)$, and it recovered completely by antimicrobial agent administration. We followed antibiotic regimen for postoperative endophthalmitis as previously reported. ${ }^{20}$ Antibacterial agents should not be administered for too long because there is a risk of creating drug-resistant bacteria, but administration for a few days according to the protocol probably prevented infectious endophthalmitis in our patients.

The present study demonstrated the current status of open globe eye injury in Japan, which is a representative country in which society is aging. In many patients, the injury was caused by an accident due to negligence or otherwise, and such patients often had a poor outcome. There were no differences between males and females with regard to injury caused by these mechanisms. In contrast, the patients with open globe eye injury due to occupational accidents were all males, and the right eye was more likely to be affected. Compared with injury due to other causes, the visual outcome was better for this kind of eye injury. In developed countries, many companies have procedures for management of occupational accidents, allowing treatment to be started early, and this may improve the outcome. We should also think about how to improve the outcome of other types of eye injury. Because the mechanism of injury, the site of injury, and the location where the injury occurs (at home or outside) vary widely, people rarely have the knowledge to correctly manage such eye injuries. Unlike occupational accidents, there is no witness to many of the eye injuries with other causes. Therefore, the mechanism of injury (what and how) may not be known, and it may be difficult to determine the extent of the injury. Injury prevention measures should be taken in the homes of elderly people, including utilization of fall-prevention aids, such as a walking frame, walking stick, or rail. In addition, the general public should be informed about basic first aid to apply if they are injured themselves or encounter a person with eye injury, such as not touching the site of injury and transporting the patient to an appropriate hospital for early treatment.

\section{Acknowledgment}

This work was supported by MEXT-Supported Program for the Strategic Research Foundation at Private Universities, 2015-2019 (Ministry of Education, Culture, Sports, Science and Technology of Japan).

\section{Disclosure}

The authors report no conflicts of interest in this work.

\section{References}

1. Stryjewski TP, Andreoli CM, Eliott D. Retinal detachment after open globe injury. Ophthalmology. 2014;121(1):327-333.

2. Pieramici DJ, Sternberg P Jr, Aaberg TM Sr, et al. A system for classifying mechanical injuries of the eye (globe). The Ocular Trauma Classification Group. Am J Ophthalmol. 1997;123:820-831.

3. Andreoli MT, Andreoli CM. Surgical rehabilitation of the open globe injury patient. Am J Ophthalmol. 2012;153(5):856-860.

4. Savar A, Andreoli MT, Kloek CE, Andreoli CM. Enucleation for open globe injury. Am J Ophthalmol. 2009;147(4):595-600.

5. Schulze-Bonsel K, Feltgen N, Burau H, Hansen L, Bach M. Visual acuities "hand motion" and "counting fingers" can be quantified with the Freiburg visual acuity test. Invest Ophthalmol Vis Sci. 2006;47(3): 1236-1240.

6. Bauza AM, Emami P, Soni N, et al. A 10-year review of assaultrelated open-globe injuries at an urban hospital. Graefes Arch Clin Exp Ophthalmol. 2013;251:653-659. 
7. Haring RS, Canner JK, Haider AH, Schneider EB. Ocular injury in the United States: emergency department visits from 2006-2011. Injury. 2016;47(1):104-108.

8. Soni NG, Bauza AM, Son JH, Langer PD, Zarbin MA, Bhagat N. Open globe ocular trauma: functional outcome of eyes with no light perception at initial presentation. Retina. 2013;33(2):380-386.

9. Chowdhury S. Injuries in marginal workers and social trauma in female: important cause of the paradigm shift in eye injury over a decade. Indian J Occup Environ Med. 2015;19(1):36-43.

10. Soliman MM, Macky TA. Pattern of ocular trauma in Egypt. Graefes Arch Clin Exp Ophthalmol. 2008;246:205-212.

11. Rofail M, Lee GA, O'Rourke P. Prognostic indicator for open globe injury. Clin Experiment Ophthalmol. 2006;34:783-786.

12. Chang CH, Chen CL, Ho CK, Lai YH, Hu RC, Yen YL. Hospitalized eye injury in a large industrial city of South-Eastern Asia. Graefes Arch Clin Exp Ophthalmol. 2008;246:223-228.

13. Mansouri M, Faghihi H, Hajizadeh F, et al. Epidemiology of open-globe injuries in Iran: analysis of 2,340 cases in 5 years (report no. 1). Retina. 2009;29:1141-1149.

14. Fea A, Bosone A, Rolle T, Grignolo FM. Eye injuries in an Italian urban population: report of 10,620 cases admitted to an eye emergency department in Torino. Graefes Arch Clin Exp Ophthalmol. 2008; 246:175-179.
15. Semeraro F, Polcini C, Forbice E et al. Work- and non-work-related eye injuries in a highly industrialized area in northern Italy: comparison between two three-year periods (1994-1996 and 2005-2007). Med Lav. 2013;104(6):467-475.

16. Desai P, Morris DS, Minassian DC, MacEwen CJ. Trends in serious ocular trauma in Scotland. Eye (Lond). 2015;29(5):611-618.

17. Justin MK, Angela VT, Michael TA, Christopher MA. Characteristics and outcomes of work-related open globe injuries. Am J Ophthalmol. 2010; 150:265-269.

18. Bauza AM, Emami P, Son JH, Langer P, Zarbin M, Bhagat N. Workrelated open-globe injuries: demographics and clinical characteristics. Eur J Ophthalmol. 2013;23(2):242-248.

19. Hotta T, Kawakami A. Pattern of handedness in modern Japanese: a cohort effect shown by readministration of the H.N. Handedness Inventory after 20 years. Can J Exp Psychol. 1995;49:505-512.

20. Olson RJ. Reducing the risk of postoperative endophthalmitis. Surv Ophthalmol. 2004;49(suppl 2):S55-S61.
Clinical Ophthalmology

\section{Publish your work in this journal}

Clinical Ophthalmology is an international, peer-reviewed journal covering all subspecialties within ophthalmology. Key topics include: Optometry; Visual science; Pharmacology and drug therapy in eye diseases; Basic Sciences; Primary and Secondary eye care; Patient Safety and Quality of Care Improvements. This journal is indexed on

\footnotetext{
Submit your manuscript here: http://www.dovepress.com/clinical-ophthalmology-journal
}

\section{Dovepress}

PubMed Central and CAS, and is the official journal of The Society of Clinical Ophthalmology (SCO). The manuscript management system is completely online and includes a very quick and fair peer-review system, which is all easy to use. Visit http://www.dovepress.com/ testimonials.php to read real quotes from published authors. 